\title{
Association of Genetic Variants in DUSP15, CNTNAP2, PCDHA Genes and the Risk of Autism Spectrum Disorder
}

Jun Liu1, Zengyu Zhang'2, Hong Yu³, Jiangying Kong ${ }^{1}$, Zhuo Liu ${ }^{4}$

${ }^{1}$ Department of Clinical Laboratory, ${ }^{3}$ Department of Child and Adolescent, Mental Health, ${ }^{4}$ Department of Internal Medicine, Zhejiang Xiaoshan Hospital, Hangzhou, China. ${ }^{2}$ Department of Pediatrics, Xiaoshan First Affiliated Hospital of Hangzhou Normal University, Hangzhou, China.

Background

Autism spectrum disorder (ASD) is a neurodevelopmental disorder characterized by social and communicative deficits and repetitive behaviors. The wide prevalence brings huge economic burden to society. Early diagnosis and intervention may improve the efficacy of the treatment. Accumulated evidence suggests genetics play an important role in the development of the disease.

Myelin is required for proper nerve transmission. Dual specificity phosphatase 15 (DUSP15) has been recognized as a key regulator gene for myelin formation [1]. Single nucleotide polymorphism (SNP) rs3746599 in DUSP15 gene has been associated with ASD in the Han Chinese population [2]. Cell surface proteins on neurons are essential for the formation of synapse and axon guidance during the early development of the neural system. The contactin associated protein-like 2 (CNTNAP2) gene encodes the neuronal cell adhesion transmembrane protein. Common variants in CNTNAP2 are associated with the severity of language and neurodevelopmental impairments [3]. Association between SNP rs7794745 in CNTNAP2 gene and ASD in Iranian population has been reported [4]. But the result is inconsistent in the Han Chinese population [5, 6]. The Protocadherins (Pcdhs) are important neuronal surface proteins. The association between SNP rs251379 in PCDHA with autism has been reported in a large cohort of 841 families with 1467 patients from the Autism Genetic Resource Exchange [7].

Though the roles of SNPs rs3746599, rs7794745 and rs251379 in the development of ASD have been determined individually in sporadic studies, the findings still need to be corroborated in different ethnical populations. This study was to determine the relationship between these SNPs and childhood ASD in the Han Chinese population.

\section{Patients and Methods}

Genotypes were examined in DNA extracted from blood cells. A total of 201 children with ASD and 200 healthy controls were recruited during 2012-2016. Children autism rating scale (CARS) was applied to determine the severity of the disease. Logistic regression was used to examine the relationship between SNPs and risk of ASD and its severity.

\section{Results}

G/G genotype of rs3746599 was significantly associated with a decreased risk of ASD $(P=0.0449)$ $\mathrm{T} / \mathrm{T}$ genotype of rs 7794745 was marginally associated with an increased risk of ASD $(P=0.0542)$. T allele of rs 7794745 was significantly associated with an increased risk of ASD ( $P=0.0435)$. In contrast, the SNP rs251379 was not associated with the risk of ASD (Table 1). All SNPs examined were not associated with the severity of childhood ASD (Table 2).

\section{Conclusions}

Both DUSP15 and CNTNAP2 may attribute to the development of childhood ASD. These SNPs as the biomarkers may help to diagnose the children with ASD. Further studies with large sample sizes are needed to validate the role of the SNPs in these genes in the development of childhood ASD.
Table 1 Correlation between genotypes and allele frequency of SNPs and childhood ASD

\begin{tabular}{rccccc}
\hline SNPs & $\begin{array}{c}\text { Genotype/ } \\
\text { Allele }\end{array}$ & $\begin{array}{c}\text { Cases } \\
\mathrm{n}(\%)\end{array}$ & $\begin{array}{c}\text { Controls } \\
\mathrm{n}(\%)\end{array}$ & $\mathrm{OR}(95 \% \mathrm{Cl})$ & $P$ value \\
\hline rs3746599 & A/A & $89(44.3)$ & $71(36.2)$ & 1 & \\
& A/G & $80(39.8)$ & $99(50.5)$ & $0.98(0.54-1.80)$ & 0.9526 \\
& G/G & $\mathbf{3 2}(\mathbf{1 5 . 9 )}$ & $\mathbf{2 6 ( 1 3 . 3 )}$ & $\mathbf{0 . 6 5 ( 0 . 4 2 - 0 . 9 9 )}$ & $\mathbf{0 . 0 4 4 9}$ \\
& $\mathrm{A}$ & $258(64.2)$ & $241(61.5)$ & 1 & \\
& $\mathrm{G}$ & $144(35.8)$ & $151(38.5)$ & $0.89(0.67-1.19)$ & 0.4314 \\
rs251379 & A/A & $45(22.4)$ & $40(20.1)$ & 1 & \\
& A/G & $92(31.8)$ & $90(45.2)$ & $0.83(0.48-1.42)$ & 0.4880 \\
& G/G & $64(45.8)$ & $68(34.7)$ & $0.91(0.54-1.52)$ & 0.7161 \\
& A & $182(45.3)$ & $170(42.7)$ & 1 & \\
rs7794745 & G & $220(54.7)$ & $228(57.3)$ & $0.90(0.68-1.19)$ & 0.4660 \\
& A/A & $60(29.9)$ & $77(38.5)$ & 1 & \\
& A/T & $102(50.8)$ & $95(47.5)$ & $1.38(0.89-2.14)$ & 0.1516 \\
& T/T & $39(19.4)$ & $28(14.0)$ & $1.79(0.99-3.23)$ & 0.0542 \\
& A & $222(55.7)$ & $249(65.3)$ & 1 & \\
& T & $\mathbf{1 8 0 ( 4 4 . 3 )}$ & $\mathbf{1 5 1 ( 3 7 . 7 )}$ & $\mathbf{1 . 3 4 ( 1 . 0 1 - 1 . 7 7 )}$ & $\mathbf{0 . 0 4 3 5}$ \\
\hline
\end{tabular}

Table 2 Correlation between genotype and allele frequencies of SNPs and severity of childhood ASD

\begin{tabular}{cccccc}
\hline SNP & $\begin{array}{c}\text { Genotype/ } \\
\text { Allele }\end{array}$ & $\begin{array}{c}\text { Mild/Moderate } \\
\mathrm{n}(\%)\end{array}$ & $\begin{array}{c}\text { Severe } \\
\mathrm{n}(\%)\end{array}$ & OR(95\% Cl) & P value \\
\hline rs3746599 & $\mathrm{A} / \mathrm{A}$ & $50(41.0)$ & $39(49.4)$ & 1 & \\
& $\mathrm{~A} / \mathrm{G}$ & $54(44.3)$ & $26(32.9)$ & $0.62(0.33-1.16)$ & 0.321 \\
& $\mathrm{G} / \mathrm{G}$ & $18(14.7)$ & $14(17.7)$ & $1.00(0.44-2.25)$ & 0.9945 \\
& $\mathrm{~A}$ & $154(63.1)$ & $104(65.8)$ & 1 & \\
& $\mathrm{G}$ & $90(36.9)$ & $54(34.2)$ & $0.89(0.58-1.35)$ & 0.5803 \\
& & & & \\
rs251379 & $\mathrm{A} / \mathrm{A}$ & $25(20.5)$ & $20(25.3)$ & 1 & \\
& $\mathrm{~A} / \mathrm{G}$ & $61(50.0)$ & $31(39.2)$ & $0.64(0.31-1.32)$ & 0.2230 \\
& $\mathrm{G} / \mathrm{G}$ & $36(29.5)$ & $28(35.4)$ & $0.97(0.45-2.10)$ & 0.9427 \\
& $\mathrm{~A}$ & $111(45.5)$ & $71(44.9)$ & 1 & \\
& $\mathrm{G}$ & $133(54.5)$ & $87(55.1)$ & $1.02(0.68-1.53)$ & 0.9131 \\
rs7794745 & $\mathrm{A} / \mathrm{A}$ & $35(29.5)$ & $25(31.7)$ & 1 & \\
& $\mathrm{~A} / \mathrm{T}$ & $60(49.2)$ & $42(53.2)$ & $0.98(0.51-1.87)$ & 0.9512 \\
& $\mathrm{~T} / \mathrm{T}$ & $27(21.3)$ & $12(15.2)$ & $0.62(0.27-1.46)$ & 0.2751 \\
& $\mathrm{~A}$ & $130(54.1)$ & $92(58.2)$ & 1 & \\
& $\mathrm{~T}$ & $114(45.9)$ & $66(41.8)$ & $0.82(0.55-1.23)$ & 0.3300 \\
\hline
\end{tabular}

